\title{
Dietary black soldier fly pulp affects growth, antioxidant and immune capacity of Micropterus salmoides
}

\author{
K. Peng ${ }^{1,2}$, W. Mo' ${ }^{1}$ H. Xiao' ${ }^{1}$ J. Hu ${ }^{1}$, X. Zhu ${ }^{1,2}$, Y. Huang ${ }^{1,2,3 *}$ and G. Wang ${ }^{*}$ \\ ${ }^{1}$ Institute of Animal Science, Guangdong Academy of Agricultural Sciences, Key Laboratory of Animal Nutrition and Feed \\ Science in South China, Ministry of Agriculture and Rural Affairs, Guangdong Provincial Key Laboratory of Animal Breeding \\ and Nutrition, Maoming Branch, Guangdong Laboratory for Lingnan Modern Agriculture, 510640, Guangzhou, China \\ P.R.; ${ }^{2}$ Guangzhou Fishtech Biotechnology Co., Ltd., 510640, Guangzhou, China P.R.; ${ }^{3}$ Innovative Institute of Animal Healthy \\ Breeding, Zhongkai University of Agriculture and Engineering, 510225, Guangzhou, China P.R.; huangyh111@126.com; \\ wanggx78@126.com
}

Received: 10 March 2021 / Accepted: 8 June 2021

(c) 2021 Wageningen Academic Publishers

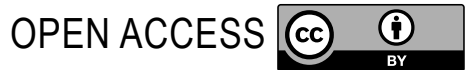

RESEARCH ARTICLE

\begin{abstract}
Dried or defatted black soldier fly (Hermetia illucens) larvae meal has been shown an important ingredient in aquafeed, but little information is available about the effects of black soldier fly pulp (BSFP) on growth and health of fish. A 62-day feeding trial was conducted to assess the effects of dietary BSFP on growth performance, whole body composition, serum metabolites, antioxidant and immune response of Micropterus salmoides. Four isoproteic and isolipidic diets were formulated by adding BSFP (original substance) to the basal diet at the rate of 0\% (BSFP0), $1 \%$ (BSFP1), 2\% (BSFP2) and 4\% (BSFP4), corresponding to inclusion of 0, 4.5, 9.0 and $18.0 \mathrm{~g} / \mathrm{kg}$ DM in diets. Each diet was randomly assigned to triplicate groups of 35 fish per tank. Fish were fed twice daily to apparent satiation. Blood samples were collected at the terminal trial to analyse serum metabolites, antioxidant and immune enzyme activities. Results indicated that fish fed BSFP2 had higher $(P<0.05)$ weight gain rate, specific growth rate and intraperitoneal fat ratio than those of fish fed other diets. Crude lipid, ash and calcium contents were higher $(P<0.05)$ in BSFP2 than those in BSFP0. Fish fed BSFP2 and BSFP4 had lower $(P<0.05)$ serum malonaldehyde but higher $(P<0.05)$ acid phosphatase than other diets. It was concluded that dietary inclusion of BSFP improved growth performance of $M$. salmoides might be attributed to increased lipid and ash deposition. BSFP improved antioxidant and immune capacity but also increased intraperitoneal fat deposition of fish, suggesting BSFP should be careful to be used in M. salmoides diets.
\end{abstract}

Keywords: black soldier fly pulp, Micropterus salmoides, growth, antioxidant, immune

\section{Introduction}

In recent years, black soldier fly (Hermetia illucens L.) has begun to play an important role in aquaculture as a promising alternative protein source and ingredient in aquafeeds due to its comparable palatability, essential amino acid pattern and nutritive value to fish meal. It has been well reported that black soldier fly is suitable to be used in diets without impairing growth performance of aquatic animals (Cummins et al., 2017; Hu et al., 2017a, 2018, 2019; Lock et al., 2016; Magalhaes et al., 2017; Renna et al., 2017; Sealey et al., 2011; Wang et al., 2019; Xiao et al., 2018; Xu et al., 2020; Zhou et al., 2017). Our previous studies demonstrated that dietary inclusion of black soldier fly larvae meal or black soldier fly larvae oil did not alter growth performance of Lateolabrax japonicus (Wang et al., 2019), Pelteobagrus fulvidraco (Hu et al., 2020; Wang et al., 2020) and Litopenaeus vannamei (Hu et al., 2019).

Black soldier fly larvae are commonly used in dried or defatted form (Hu et al., 2019, 2020; Li et al., 2017; Wang et al., 2019, 2020) in aquafeeds. However, it is easy to understand that drying and defatting may lead to nutrition loss of larvae and extra costs during commercial processing, 
such as lipid oxidation caused by drying, or lipid and amino acid loss during defatting, as summarised from results of our previous studies (Hu et al., 2017a,b; Wang et al., 2019, 2021). On the contrary, black soldier fly pulp (BSFP) used in this study was directly made from fresh and clean larvae and its nutrient value is close to the nature. BSFP saved processing technology and equipment and thus saved costs of feed when considering commercial production. For another reason, BSFP is suitable to be used as aquafeed because insects are historically regard as much of the basic prey for omnivorous and carnivorous fish (Henry et al., 2015; Nogales-Merida et al., 2019), although there would also be negative to using BSFP such as the increased transport cost due to weight of water and the decreased durability of the insect ingredient before used in feed. Nevertheless, evaluation about the effects of BSFP on growth and health of fish remain rare. Only a recent study by Xu et al. (2020) documented that BSFP at the level below $131 \mathrm{~g} / \mathrm{kg}$ could be added in diet of juvenile mirror carp (Cyprinus carpio var. specularis) without any negative effects on growth performance and intestinal health. However, to our best knowledge, research has not been conducted in carnivorous fish species. Our previous studies in black soldier fly larvae meal showed inconsistent results in growth and antioxidant capacity between omnivorous (Ctenopharyngodon idellus) and carnivorous (L. japonicus) fish (Huang et al., 2019; Wang et al., 2019), depending on larvae forms and inclusion levels in diets.

Micropterus salmoides, also known as California perch, is one of the most commercially valuable carnivorous species that has been widely cultured worldwide. In 2019, China contributed nearly 500,000 tons of the freshwater farmed M. salmoides (China Fishery Statistical Yearbook, 2020). The objective of this study was to evaluate the effects of BSFP on the growth performance, whole body composition, serum metabolites, antioxidant and immune capacity of M. salmoides.

\section{Materials and methods}

\section{Diet preparation}

The proximate and nutrient composition of the experimental diets was shown in Table 1 and the chemical composition of BSFP (obtained from Guangzhou Anruijie Environmental Protection Technology Co. Ltd., Guangzhou, China) was as follows: dry matter $40 \%$, crude protein $14 \%$, crude lipid $15 \%$, ash $5 \%$ and chitin $2 \%$. The BSFP (original substance) was added to the basal diet at the rate of $0 \%$ (BSFP0), $1 \%$ (BSFP1), 2\% (BSFP2) and 4\% (BSFP4), corresponding to inclusion of 0, 4.5, 9.0 and $18.0 \mathrm{~g} / \mathrm{kg}$ DM in diets. All diets were extruded using the Valva-60 extruder (Guangzhou Valva Machinery Equipment Co. Ltd, Guangzhou, China) into $2 \mathrm{~mm}$ pellets, dried at $55^{\circ} \mathrm{C}$ overnight and stored at $-20^{\circ} \mathrm{C}$
Table 1. Ingredients and proximate composition of the experimental diets. ${ }^{1}$

\begin{tabular}{lcccc} 
Ingredients (g/kg DM) & BSFP0 & BSFP1 & BSFP2 & BSFP4 \\
Fish meal & & & & \\
Black soldier fly pulp & 450 & 450 & 450 & 450 \\
Soy protein concentrate & 225 & 225 & 225 & 220 \\
Peeled soybean meal & 110 & 110 & 110 & 110 \\
Alpha starch & 124 & 119.5 & 115 & 111 \\
Fish oil & 40 & 40 & 40 & 40 \\
Soya oil & 20 & 20 & 20 & 20 \\
Monocalcium phosphate & 15 & 15 & 15 & 15 \\
Vitamin premix ${ }^{2}$ & 1 & 1 & 1 & 1 \\
Mineral premix & 5 & 5 & 5 & 5 \\
Vitamin C ester & 3 & 3 & 3 & 3 \\
Choline chloride & 5 & 5 & 5 & 5 \\
Methionine & 2 & 2 & 2 & 2 \\
Proximate composition & & & & \\
$\quad$ Dry matter & 952 & 949 & 947 & 948 \\
Crude protein & 504.2 & 509.0 & 510.5 & 508.5 \\
Crude lipid & 94.7 & 93.9 & 94.4 & 96.4 \\
Ash & 111 & 110 & 110 & 111 \\
\hline
\end{tabular}

${ }^{1}$ BSFP0-BSFP4, percentage of black soldier fly pulp included in the basal diet were $0,1,2$ and $4 \%$, respectively.

2 One kilogram of vitamin premix provided: VA 3,230,000 IU, VD 1,600,000 IU, VE $16 \mathrm{~g}, V_{3} 4 \mathrm{~g}, V_{1} 4 \mathrm{~g}, V_{2} 8 \mathrm{~g}, \mathrm{VB}_{6} 4.8 \mathrm{~g}, V_{12} 0.016 \mathrm{~g}$, nicotinic acid 28 $\mathrm{g}$, pantothenic acid calcium $16 \mathrm{~g}$, biotin $0.064 \mathrm{~g}$, folic acid $1.285 \mathrm{~g}$, inositol $40 \mathrm{~g}$.

${ }^{3}$ One kilogram of vitamin premix provided: Ca $230 \mathrm{~g}, \mathrm{~K} 36 \mathrm{~g}, \mathrm{Mg} 9 \mathrm{~g}, \mathrm{Fe} 10$ g, Zn 8 g, Mn 1.9 g, Cu 1.5 g, Co 0.25 g, I 0.032 g, Se 0.05 g.

\section{Experimental design and feeding management}

The experimental fish were provided by the Institute of Animal Science, Guangdong Academy of Agricultural Sciences (Guangzhou, China). A total of 420 healthy M. salmoides (initial body weight $4.9 \pm 0.10 \mathrm{~g}$ ) were randomly distributed into 4 groups with triplicate per group, and assigned to 12 tanks with 35 fish in each tank. Fish were fed to apparent satiation twice daily (07:00 and 19:00) during the 62-d feeding trial. Orts and faeces were siphoned out daily before morning feeding. Feed intake (FI) was calculated as the difference between the amount of feed offered and orts. During the 62-d trial, the water quality was kept at dissolved oxygen $>5 \mathrm{mg} / \mathrm{l}$, water temperature $27-30{ }^{\circ} \mathrm{C}$, $\mathrm{pH}$ 7.6-7.9, ammonia $\leq 0.1 \mathrm{mg} / \mathrm{l}$ and nitrite $\leq 0.01 \mathrm{mg} / \mathrm{l}$.

\section{Sampling}

Prior to sampling, all fish were fasted for $24 \mathrm{~h}$ and then anaesthetised with $40 \mathrm{mg} / \mathrm{l}$ of tricaine methanesulfonate. Fish per tank were counted and weighted to determine for final body weight (FBW), weight gain rate (WGR), FI, feed 
conversion ratio (FCR), and specific growth rate (SGR). Three fish in each tank were randomly collected to analyse for body composition.

Blood was collected from the caudal veins of 15 fish in each tank, samples were pooled per tank and then centrifuged at $3,500 \mathrm{r} / \mathrm{min}$ for $10 \mathrm{~min}$. The resultant serum was collected to determine serum parameters. Six fish per tank were randomly collected, slaughtered and measured for condition factor (CF), viscerosomatic index (VSI), hepatosomatic index (HSI), intestinesomatic index (ISI), and intraperitoneal fat ratio (IFR).

\section{Laboratory analyses}

The nutrient composition of BSFP, diets and fish were determined using AOAC method (AOAC, 1999). Dry matter was analysed by drying samples to a constant weight at $105{ }^{\circ} \mathrm{C}$. Crude protein was measured using the Kjeldahl method. Crude lipid was determined according to the Soxhlet method. Ash was measured by combustion at $550{ }^{\circ} \mathrm{C}$ for $6 \mathrm{~h}$. Calcium and total $\mathrm{P}$ were determined using method as described by Hu et al. (2018). Chitin was analysed as D-glucosamine using the method described by Madrid et al. (2013).

Serum metabolites were measured using Hitachi 7180 Biochemical Analyzer (Tokyo, Japan). Antioxidant and immune parameters were determined using commercial kits provided by the Nanjing Jiancheng Bioengineering Institute (Nanjing, China).

\section{Data calculations and statistical analysis}

All data were summarised and averaged for each tank and parameters were calculated as follows:

1. WGR $(\%)=100 \times(\mathrm{FBW}(\mathrm{g})-\mathrm{IBW}(\mathrm{g})) / \mathrm{IBW}(\mathrm{g})$

2. FI $(\mathrm{g} /$ fish $)=$ feed consumed $(\mathrm{g}) /($ final fish number + initial fish number) $/ 2$

3. FCR $=$ FI (g) / (FBW (g) - IBW (g))

4. SGR $(\% / d)=100 \times(\ln$ FBW $(\mathrm{g})-\ln \mathrm{IBW}(\mathrm{g})) /$ days

5. SR $(\%)=100 \times$ (final fish number) / (initial fish number)

6. CF $\left(\mathrm{g} / \mathrm{cm}^{3}\right)=$ body weight $(\mathrm{g}) /$ body length ${ }^{3}(\mathrm{~cm})$

7. VSI $(\%)=100 \times$ visceral weight $(\mathrm{g}) /$ body weight $(\mathrm{g})$

8. HSI $(\%)=100 \times$ hepatopancreas weight $(\mathrm{g}) /$ body weight (g)

9. ISI $(\%)=100 \times$ intestine weight $(\mathrm{g}) /$ body weight $(\mathrm{g})$

10. IFR $(\%)=100 \times$ intraperitoneal fat weight $(\mathrm{g}) /$ body weight $(\mathrm{g})$

Tank was used as the statistical unit. All data were subjected to a one-way ANOVA using SPSS 17.0 followed by the Tukey test. Significant differences were declared at $P<0.05$ and the results are shown as means $\pm \mathrm{SE}$.

\section{Results}

\section{Growth performance and body composition}

Fish fed BSFP2 had higher $(P<0.05)$ FBW, WGR, SGR and IFR than those of fish fed other diets (Table 2). All fish had similar $(P>0.05)$ IBW, FI, FCR, SR, CF, VSI, HIS and ISI. The content of $C L$ and ash were higher $(P<0.05)$ in fish fed BSFP2 than those of fish fed BSFP0 (Table 3). Fish fed BSFP2 and BSFP4 had higher $(P<0.05)$ level of $\mathrm{Ca}$ than those of fish fed BSFP0.

\section{Serum metabolites, antioxidant and immune response}

Fish had similar $(P>0.05)$ total cholesterol, triacylglycerol, albumin, globulin, glucose, blood urea nitrogen, aspartate aminotransferase, alanine aminotransferase, low density lipoprotein cholesterol and high density lipoprotein cholesterol(Table 4), and similar total antioxidant capacity, catalase (CAT), glutathione peroxidase, superoxide dismutase, alkaline phosphatase and lysozyme regardless of the treatments (Table 5). Fish fed BSFP2 and BSFP4 had lower $(P<0.05)$ malondialdehyde $(\mathrm{MDA})$ but higher $(P<0.05)$ acid phosphatase (ACP) than those of fish fed other diets.

\section{Discussion}

\section{Growth performance and body composition}

Black soldier fly larvae have been shown an important ingredient in aquafeed, whereas little information is available about the effects of BSFP on growth and health of fish. The similar feed intake and survival rate of fish among diets in this study suggested that BSFP was palatable for $M$. salmoides. Similar results have been observed when BSFP was included in the mirror carp (C. carpio var. specularis) diets (Xu et al., 2020). Significantly increased weight gain rate and specific growth rate in BSFP2 as compared with other diets indicated that dietary inclusion of $9 \mathrm{~g} / \mathrm{kg}$ DM BSFP improved growth performance of $M$. salmoides. Previous studies have been well documented that black soldier fly larvae could be partly or fully replace fishmeal in aquafeeds without impairing growth performance of rainbow trout (Oncorhynchus mykiss) (Renna et al., 2017; Sealey et al., 2011), Atlantic salmon (Salmo salar) (Lock et al., 2016), European seabass (Dicentrarchus labrax) (Magalhaes et al., 2017), Pacific white shrimp (L. vannamei) (Cummins et al., 2017; Hu et al., 2019), Jian carp (C. carpio var. Jian) (Zhou et al., 2017), tilapia (Muin et al., 2017), koi cap (C. carpio) (Liu et al., 2017a), yellow catfish (P. fulvidraco) (Hu et al., 2017a; Wang et al., 2020; Xiao et al., 2018) and Japanese seabass (L. japonicus) (Hu et al., 2018; Wang et al., 2019). Xu et al. (2020) also reported that up to $174.7 \mathrm{~g} / \mathrm{kg}$ DM BSFP in diets had no negative effect on growth performance of mirror carp (C. carpio var. specularis). However, Cummins et al. (2017) found 
Table 2. Effect of inclusion of black soldier fly pulp (BSFP) on growth performance of Micropterus salmoides. ${ }^{1,2}$

\begin{tabular}{|c|c|c|c|c|}
\hline & BSFPO & BSFP1 & BSFP2 & BSFP4 \\
\hline IBW (g) & $4.89 \pm 0.01$ & $4.89 \pm 0.01$ & $4.90 \pm 0.01$ & $4.89 \pm 0.01$ \\
\hline FBW (g) & $56.71 \pm 1.66^{b}$ & $58.27 \pm 1.12^{b}$ & $64.01 \pm 0.90^{\mathrm{a}}$ & $59.02 \pm 1.85^{b}$ \\
\hline WGR (\%) & $1,059.71 \pm 34.31^{b}$ & $1,091.62 \pm 22.97^{b}$ & $1,206.33 \pm 19.66^{a}$ & $1,107.20 \pm 37.59^{b}$ \\
\hline $\mathrm{FI}$ (g/fish) & $39.96 \pm 1.96$ & $41.06 \pm 0.77$ & $42.69 \pm 1.16$ & $39.98 \pm 0.85$ \\
\hline FCR & $0.77 \pm 0.01$ & $0.77 \pm 0.02$ & $0.72 \pm 0.02$ & $0.74 \pm 0.01$ \\
\hline SGR (\%) & $3.95 \pm 0.05^{b}$ & $3.99 \pm 0.03^{b}$ & $4.15 \pm 0.02^{\mathrm{a}}$ & $4.01 \pm 0.01^{b}$ \\
\hline SR $(\%)$ & $94.30 \pm 3.29$ & $90.57 \pm 2.87$ & $97.13 \pm 1.65$ & $97.13 \pm 1.65$ \\
\hline $\mathrm{CF}\left(\mathrm{g} / \mathrm{cm}^{3}\right)$ & $2.40 \pm 0.13$ & $2.44 \pm 0.15$ & $2.44 \pm 0.18$ & $2.39 \pm 0.11$ \\
\hline VSI (\%) & $6.94 \pm 0.90$ & $7.35 \pm 0.98$ & $7.63 \pm 1.16$ & $7.51 \pm 1.04$ \\
\hline HSI (\%) & $2.42 \pm 0.88$ & $2.66 \pm 0.77$ & $2.59 \pm 0.71$ & $2.77 \pm 0.84$ \\
\hline ISI (\%) & $0.56 \pm 0.11$ & $0.60 \pm 0.09$ & $0.61 \pm 0.08$ & $0.56 \pm 0.07$ \\
\hline IFR $(\%)$ & $1.34 \pm 0.31^{b}$ & $1.47 \pm 0.37^{b}$ & $1.81 \pm 0.45^{a}$ & $1.57 \pm 0.28^{\mathrm{ab}}$ \\
\hline
\end{tabular}

Table 3. Effect of inclusion of black soldier fly pulp (BSFP) on body composition (\% original substance) of Micropterus salmoides. ${ }^{1,2}$

\begin{tabular}{llccc} 
& BSFP0 & BSFP1 & BSFP2 & BSFP4 \\
DM & $27.91 \pm 0.67$ & $28.02 \pm 0.21$ & $29.05 \pm 0.35$ & $28.64 \pm 0.45$ \\
CP & $17.26 \pm 0.11$ & $17.57 \pm 0.48$ & $17.86 \pm 0.40$ & $17.61 \pm 0.23$ \\
CL & $4.90 \pm 0.51^{\mathrm{b}}$ & $5.96 \pm 0.18^{\mathrm{ab}}$ & $6.34 \pm 0.11^{\mathrm{a}}$ & $5.99 \pm 0.42^{\mathrm{ab}}$ \\
Ash & $3.27 \pm 0.06^{\mathrm{b}}$ & $3.54 \pm 0.15^{\mathrm{ab}}$ & $3.75 \pm 0.13^{\mathrm{a}}$ & $3.65 \pm 0.14^{\mathrm{ab}}$ \\
Ca & $0.70 \pm 0.02^{\mathrm{b}}$ & $0.86 \pm 0.04^{\mathrm{ab}}$ & $0.96 \pm 0.08^{\mathrm{a}}$ & $0.94 \pm 0.08^{\mathrm{a}}$ \\
Total P & $0.61 \pm 0.06$ & $0.54 \pm 0.07$ & $0.68 \pm 0.02$ & $0.62 \pm 0.02$ \\
\hline
\end{tabular}

${ }^{1}$ BSFP0-BSFP4, percentage of black soldier fly pulp included in the basal diet were $0,1,2$ and $4 \%$, respectively. $\mathrm{Ca}=\mathrm{calcium} ; \mathrm{CL}=\mathrm{crude}$ lipid; $\mathrm{CP}=\mathrm{crude}$ protein; $\mathrm{DM}=$ dry matter; $\mathrm{P}=$ phosphorus.

${ }^{2}$ Means with different letters differ $(P<0.05)$.

Table 4. Effect of inclusion of black soldier fly pulp (BSFP) on serum metabolites of Micropterus salmoides. ${ }^{1}$

\begin{tabular}{lllll} 
& BSFP0 & BSFP1 & BSFP2 & BSFP4 \\
TCHO $(\mathrm{mmol} / \mathrm{l})$ & $7.57 \pm 0.80$ & $7.78 \pm 0.54$ & $6.30 \pm 0.14$ & $7.69 \pm 0.63$ \\
TG $(\mathrm{mmol} / \mathrm{l})$ & $2.65 \pm 0.08$ & $3.22 \pm 1.01$ & $2.17 \pm 0.09$ & $2.86 \pm 0.31$ \\
ALB $(\mathrm{g} / \mathrm{l})$ & $8.80 \pm 0.17$ & $9.33 \pm 0.49$ & $10.53 \pm 0.27$ & $9.50 \pm 1.06$ \\
$\mathrm{GLB}(\mathrm{g} / \mathrm{l})$ & $14.90 \pm 0.97$ & $16.50 \pm 0.78$ & $16.37 \pm 0.43$ & $15.20 \pm 0.26$ \\
$\mathrm{GLU}(\mathrm{mmol} / \mathrm{l})$ & $6.24 \pm 0.65$ & $4.76 \pm 0.82$ & $6.18 \pm 0.19$ & $5.63 \pm 1.11$ \\
BUN $(\mathrm{mmol} / \mathrm{l})$ & $4.27 \pm 0.57$ & $3.67 \pm 0.07$ & $3.53 \pm 0.33$ & $3.93 \pm 0.07$ \\
AST $(\mathrm{U} / \mathrm{l})$ & $122.33 \pm 6.84$ & $120.33 \pm 12.14$ & $125.33 \pm 8.09$ & $116.33 \pm 6.74$ \\
ALT $(\mathrm{U} / \mathrm{l})$ & $1.67 \pm 0.33$ & $2.00 \pm 0.58$ & $2.00 \pm 0.00$ & $1.67 \pm 0.33$ \\
LDLC $(\mathrm{mmol} / \mathrm{l})$ & $2.07 \pm 0.39$ & $2.13 \pm 0.26$ & $1.92 \pm 0.02$ & $2.33 \pm 0.39$ \\
HDLC $(\mathrm{mmol} / \mathrm{l})$ & $1.59 \pm 0.11$ & $1.59 \pm 0.20$ & $1.54 \pm 0.02$ & $1.57 \pm 0.09$ \\
\hline
\end{tabular}

\footnotetext{
${ }^{1}$ BSFP0-BSFP4, percentage of black soldier fly pulp included in the basal diet were $0,1,2$ and $4 \%$, respectively. ALB = albumin; $A L T=$ alanine aminotransferase; AST = aspartate aminotransferase; $\mathrm{BUN}=$ blood urea nitrogen; $\mathrm{GLB}=$ globulin; $\mathrm{GLU}=$ glucose; $\mathrm{HDLC}=$ high density lipoprotein cholesterol; $\mathrm{LDLC}=$ low density lipoprotein cholesterol; $\mathrm{TCHO}=$ total cholesterol; $\mathrm{TG}=$ triacylglycerol.
} 
Table 5. Effect of inclusion of black soldier fly pulp (BSFP) on serum antioxidant and immune response of Micropterus salmoides. ${ }^{1,2}$

BSFP0

$12.88 \pm 0.74$
$5.45 \pm 1.43$
$2,504.51 \pm 48.91$
$173.62 \pm 21.55$
$9.82 \pm 0.54^{a}$

$14.67 \pm 1.22$
$7.25 \pm 0.09^{b}$
$71.11 \pm 5.51$

$71.11 \pm 5.51$
BSFP1

$11.34 \pm 0.83$

$5.81 \pm 0.25$

$2,674.26 \pm 34.36$

$159.44 \pm 10.58$

$9.66 \pm 0.78^{a}$

$\operatorname{MDA}(\mathrm{nmol} / \mathrm{ml})$

Immune (U/ml)

AKP

ACP

LZM

$13.87 \pm 1.02$
$7.37 \pm 0.14^{b}$
$77.17 \pm 5.85$

BSFP2

$12.50 \pm 0.50$
$4.92 \pm 0.32$
$2,846.46 \pm 44.39$
$198.14 \pm 1.75$
$7.62 \pm 0.96^{b}$

$12.64 \pm 0.60$

$7.84 \pm 0.12^{\mathrm{a}}$

$71.56 \pm 3.62$
BSFP4

$10.97 \pm 0.20$
$5.33 \pm 0.22$
$2,666.41 \pm 78.45$
$168.60 \pm 9.45$
$5.29 \pm 0.54^{c}$

$13.82 \pm 0.97$
$7.74 \pm 0.05^{a}$
$67.98 \pm 1.47$

$10.97 \pm 0.20$

$2,666.41 \pm 78.45$

$168.60 \pm 9.45$

${ }^{1}$ BSFP0-BSFP4, percentage of black soldier fly pulp included in the basal diet were $0,1,2$ and $4 \%$, respectively. ACP = acid phosphatase; $A K P=$ alkaline phosphatase; $\mathrm{CAT}=$ catalase; $\mathrm{GPx}=$ glutathione peroxidase $\mathrm{LZM}=$ lysozyme; $\mathrm{MDA}=$ malondialdehyde; $\mathrm{SOD}=$ superoxide dismutase; $\mathrm{TAOC}=$ total antioxidant capacity .

${ }^{2}$ Means with different letters differ $(P<0.05)$.

that inclusion of black soldier fly larvae in shrimp diets depressed growth performance when the replacement rate of fishmeal by black soldier fly larvae meal exceeded $25 \%$. Wang et al. (2020) observed decreased growth performance of yellow catfish (P. fulvidraco) when the replacement rate of fishmeal by black soldier fly larvae meal exceeded $40 \%$. In this study, reduced growth performance observed in BSFP4 was most likely due to increased chitin as dietary BSFP increasing. Chitin was reported to inhibit nutrient absorption resulting in reduced growth performance of fish (Shiau and Yu, 1999). Even lower content of chitin (1\%) can decrease growth performance of carp and Atlantic salmon (Gopalakannan and Arul, 2006; Olsen et al., 2006). In summary, these discrepancies observed on the effects of black soldier fly larvae on growth performance among studies may have resulted from variations in diet formulations and/or differences in animal species.

It is interesting to note that dietary inclusion of $9 \mathrm{~g} / \mathrm{kg}$ DM BSFP increased the intraperitoneal fat ratio and crude lipid content of $M$. salmoides, suggesting that BSFP could promote fat deposition. This is unlikely attributed to nutrient levels of diets because all diets in this study were formulated to be isoproteic and isolipidic. Our previous studies observed that dietary inclusion of full fat or defatted black soldier fly larvae meal did not alter fat deposition of fish (Wang et al., 2019) or even inhibit fat deposition (Wang et al., 2020). However, research on BSFP remain rare. A recent study by Xu et al. (2020) reported that dietary inclusion of BSFP up to $174.7 \mathrm{~g} / \mathrm{kg}$ DM had no influence on the intraperitoneal fat index but decreased whole body crude lipid content of mirror carp (C. carpio var. specularis). Differences between this study and Xu et al. (2020) may due to variations in fish species or differences in BSFP inclusion levels. The inclusion level of $\mathrm{BSFP}$ is $4.5-18.0 \mathrm{~g} / \mathrm{kg} \mathrm{DM}$ in this study, which is much lower than 43.7-174.7 g/kg DM in Xu et al. (2020). Furthermore, black soldier fly larvae contain high level of saturated and monounsaturated fatty acids which is quite different from fishmeal. It has been reported that high level of saturated and monounsaturated fatty acids is usually conducive to fat accumulation (Yi, 2018). Moreover, the larvae used in this study reared on kitchen waste substrate had higher crude lipid content than those of larvae fed wheat bran (Xu et al., 2020) or other substances (Hu et al., 2017b). Yi (2018) reported that increased inclusion level of black soldier fly larvae oil in yellow catfish ( $P$. fulvidraco) diets increased the saturated and monounsaturated fatty acid deposition. In this study, the increased whole body crude lipid content in BSFP2 is most likely attribute to correspondingly increased intraperitoneal fat ratio. Increased whole body crude lipid content by inclusion of black soldier fly larvae in diets has also been reported in shrimp (L. vannamei) (Hu et al., 2019) and Japanese seabass (L. japonicus) (Hu et al., 2018). Similarly, increased whole body ash and $\mathrm{Ca}$ levels in BSFP2 as compared with BSFP0 suggested that inclusion of black soldier fly larvae in $M$. salmoides diets promote Ca deposition. This is consistent with our previous observation by $\mathrm{Hu}$ et al. $(2019,2020)$. Furthermore, the increased intraperitoneal fat along with increased body composition of fish fed BSFP treated diets may partly account for improved growth performance of $M$. salmoides.

\section{Serum antioxidant and immune response}

The similar serum metabolites among diets suggests dietary inclusion of BSFP up to $18 \mathrm{~g} / \mathrm{kg}$ DM did not adversely impact on these metabolite profiles. However, decreased MDA concentration as dietary BSFP increasing indicated that inclusion of BSFP may enhance the antioxidant capacity of $M$. salmoides. MDA is a product of polyunsaturated fatty acid peroxidation and directly reflects the degree of 
endogenous oxidative damage (Ding et al., 2015). Buege and Aust (1978) reported that increased MDA can result in tissue damage. Decreased serum MDA concentration has also been observed in Jian carp (C. carpio var. Jian) fed black soldier fly larvae meal (Zhou et al., 2017) and Japanese seabass (L. japonicus) fed defatted black soldier fly larvae meal (Wang et al., 2019). A recent study by Xu et al., (2020) reported that dietary inclusion of BSFP improved antioxidant status of mirror carp (C. carpio var. specularis) by increasing serum CAT activity and decreasing MDA concentration. Improved antioxidant status of $M$. salmoides by inclusion of BSFP in this study is likely due to the antioxidant effect of chitin. Kroeckel et al. (2012) reported that black soldier fly larvae contain polysaccharide chitin in their exoskeleton. Chitin was found to have antioxidant properties (Ngo and Kim, 2014; Ngo et al., 2009). ACP is an important enzyme of animal lysosomes (Blasco et al., 1993). This study showed that dietary inclusion of BSFP at $9 \mathrm{~g} / \mathrm{kg}$ DM increased serum ACP activity, suggesting that BSFP may enhance immune capacity of $M$. salmoides. This is consistent with observation by Xiao et al. (2018) in yellow catfish (P. fulvidraco) that dietary inclusion of black soldier fly larvae meal improved immune capacity of fish, owing the contribution to the presence of chitin in the larvae. Another reason for the increased antioxidant and immune capacity by BSFP in this study is likely due to increased lauric acid as dietary BSFP increasing. Black soldier fly was reported to contains 19.2 and $9.7 \%$ of lauric acid (\% of total fatty acid) from insect oil (Hu et al., 2020) and insect meal (Hu et al., 2017b), respectively. Lauric acid or its derivative glycerol monolaurate has been shown to have an effect as antioxidant and immune modulator (Liu et al., 2017b; Sun et al., 2021) owing to its activation on antioxidant and immune system. Also, vitamins, peptides, or other antioxidants not known or described in the insect pulp may contribute to the improved antioxidant and immune capacity although these active substances have not been determined in this study. Further study is still needed to confirm this.

\section{Conclusions}

Dietary inclusion of 2\% BSFP improved growth performance of $M$. salmoides might be attributed to increased lipid and ash deposition. BSFP improved antioxidant and immune capacity but also increased intraperitoneal fat deposition of fish, suggesting BSFP should be careful to be used in $M$. salmoides diets.

\section{Acknowledgements}

This study was funded by Guangzhou Science and Technology Project (202002020018); Guangdong Modern Technology System of Agricultural Industry, Innovation Team of Feed Industry Technology System of Guangdong (2020KJ115); Science and Technology Program of Guang- dong Province (2019A050505007); Special Fund for Scientific Innovation Strategy-Construction of High-Level Academy of Agriculture Science (R2018QD-075). Authors would also like to thank reviewers for their constructive comments to improve the quality of this article.

\section{Conflicts of interest}

The authors declare no conflict of interest.

\section{References}

Association of Official Analytical Chemists (AOAC), 1999. Official methods of analysis of the association of official agricultural chemists, $16^{\text {th }}$ edition. AOAC International, Gaithersburg, MD, USA.

Blasco, J., Puppo, J. and Sarasquete, M.C., 1993. Acid and alkaline phosphatase activities in the clam Ruditapes philippinarum. Marine Biology 115(1): 113-118.

Buege, J.A. and Aust, S.D., 1978. Microsomal lipid peroxidation. Methods in Enzymology 52: 302-310.

China Fishery Statistical Yearbook, 2020. Fishery Bureau. Ministry of Agriculture. China Agriculture Press, Beijing, China.

Cummins, V.C., Rawles, S.D., Thompson, K.R., Velasquez, A., Kobayashi, Y., Hager, J. and Webster, C.D., 2017. Evaluation of black soldier fly (Hermetia illucens) larvae meal as partial or total replacement of marine fish meal in practical diets for Pacific white shrimp (Litopenaeus vannamei). Aquaculture 473: 337-344.

Ding, Z., Zhang, Y., Ye, J., Du, Z. and Kong, Y., 2015. An evaluation of replacing fish meal with fermented soybean meal in the diet of Macrobrachium nipponense: growth, nonspecific immunity, and resistance to Aeromonas hydrophila. Fish and Shellfish Immunology 44: 295-301.

Gopalakannan, A. and Arul, V., 2006. Immunomodulatory effects of dietary intake of chitin, chitosan and levamisole on the immune system of Cyprinus carpio and control of Aeromonas hydrophila infection in ponds. Aquaculture 255: 179-187.

Henry, M., Gasco, L., Piccolo, G. and Fountoulaki, E., 2015. Review on the use of insects in the diet of farmed fish: past and future. Animal Feed Science and Technology 203: 1-22.

Hu, J., He, F., Mo, W., Chen, X., Huang, Y., Wang, G. and Sun, Y., 2017b. Analysis of the feed value of black soldier fly larvae fed on different organic wastes. China Feed 15: 24-27.

Hu, J., Wang, G., Huang, W., Zhao, H., Mo, W. and Huang, Y., 2019. Effects of fish meal replacement by black soldier fly (Hermetia illucens) larvae meal on growth performance, body composition, serum biochemical indexes and antioxidant ability of juvenile Litopenaeus vannamei. Chinese Journal of Animal Nutrition 31: 5292-5300.

Hu, J., Wang, G., Mo, W., Huang, Y., Li, G., Li, Y., Sun, Y. and Zhao, H., 2018. Effects of fish meal replacement by black soldier fly (Hermetia illucens L.) larvae meal on growth performance, body composition, plasma biochemical indexes and tissue structure of juvenile Lateolabrax japonicas. Chinese Journal of Animal Nutrition 30: 613-623. 
Hu, J., Yi, C., Wang, G., Mo, W. and Huang, Y., 2020. Effects of soybean oil replacement by black soldier fly (Hermetia illucens) larvae oil on growth performance, plasma biochemical indexes and liver lipid droplets of juvenile yellow catfish (Peltobagrus fulvidraco). Acta Hydrobiologica Sinica 44(4): 717-727.

Hu, J.R., Wang, G.X., Huang, Y.H., Sun, Y.P., He, F., Zhao, H.X. and Li, N.N., 2017a. Effects of substitution of fish meal with black soldier fly (Hermetia illucens) larvae meal, in yellow catfish (Pelteobagrus fulvidraco) diets. Israeli Journal of Aquaculture-Bamidgeh 69: 1-9.

Huang, W., Huang, Y., Mi, H., Zhao, H., Wen, Y., Sun, Y., Wang, G., $\mathrm{Hu}, \mathrm{J}$. and Wang, Y., 2019. Effects of fishmeal replacement by three animal protein sources on growth performance, muscle nutritional components, digestive enzyme activities and serum biochemical and antioxidant indices of Ctenopharyngodon idellus. Chinese Journal of Animal Nutrition 31(5): 2187-2200.

Kroeckel, S., Age, H., Roth, I., Katz, H., Wuertz, S., Susenbeth, A. and Schulz, C., 2012. When a turbot catches a fly: evaluation of a pre-pupae meal of the black soldier fly (Hermetia illucens) as fish meal substitute - growth performance and chitin degradation in juvenile turbot (Psetta maxima). Aquaculture 364-365: 345-352.

Li, S., Ji, H., Zhang, B., Zhou, J. and Yu, H., 2017. Defatted black soldier fly (Hermetia illucens) larvae meal in diets for juvenile Jian carp (Cyprinus carpio var. Jian): growth performance, antioxidant enzyme activities, digestive enzyme activities, intestine and hepatopancreas histological structure. Aquaculture 477: 62-70.

Liu, M., Wang, J. and Feng, F., 2017b. Effects of glycerol monolaurate on production performance, egg quality, serum parameters, immune organ index and abdominal fat morphology of laying hens. China Poultry 39(17): 24-30.

Liu, X., Sun, X.L., Li, L.X., Zhang, Y. and Chen, J.C., 2017a. Effects of dietary fish meal replaced by Hermetia illucens meal on growth and health of koi cap (Cyprinus carpio). Journal of Dalian Ocean University 32(4): 422-427.

Lock, E.R., Arsiwalla, T. and Waagbo, R., 2016. Insect larvae meal as an alternative source of nutrients in the diet of Atlantic salmon (Salmo salar) postsmolt. Aquaculture Nutrition 22(6): 1202-1213.

Madrid, J., Martínez, S., López, C., Orengo, J., López, M.J. and Hernández, F., 2013. Effects of low protein diets on growth performance, carcass traits and ammonia emission of barrows and gilts. Animal Production Science 53(2): 146-153.

Magalhaes, R., Sanchez-Lopez, A., Leal, R.S., Martínez-Llorens, S., Oliva-Teles, A. and Peres, H., 2017. Black soldier fly (Hermetia illucens) pre-pupae meal as a fish meal replacement in diets for European seabass (Dicentrarchus labrax). Aquaculture 476: 79-85.

Muin, H., Taufek, N.M., Kamarudin, M.S. and Razak, S.A., 2017. Growth performance, feed utilization and body composition of Nile tilapia, Oreochromis niloticus (Linnaeus, 1758) fed with different levels of black soldier fly, Hermetia illucens (Linnaeus, 1758) maggot meal diet. Iranian Journal of Fisheries Sciences 16: 567-577.

Ngo, D.H. and Kim, S.K., 2014. Antioxidant effects of chitin, chitosan and their derivatives. Advances in Food and Nutrition Research 73: 15-31.

Ngo, D.N., Lee, S.H., Kim, M.M. and Kim, S.K., 2009. Production of chitin oligosaccharides with different molecular weights and their antioxidant effect in raw 264.7 cells. Journal of Functional Foods 1: $188-198$
Nogales-Merida, S., Gobbi, P., Jozefiak, D., Mazurkiewicz, J., Dudek, K., Rawski, M., Kieronczyk, B. and Jozefiak, A., 2019. Insect meals in fish nutrition. Reviews in Aquaculture 11: 1080-1103.

Olsen, R., Suontama, J., Langmyhr, E., Mundheim, H., Ringo, E., Melle, E., Malde, M. and Hmere, G., 2006. The replacement of fish meal with Antarctic krill, Euphausia superba in diets for Atlantic salmon, Salmo salar. Aquaculture Nutrition 12: 280-290.

Renna, M., Schiavone, A., Gai, F., Dabbou, S., Lussiana, C., Malfatto, V., Prearo, M., Capucchio, M.T., Biasato, I., Biasibetti, E., De Marco M., Brugiapaglia, A., Zoccarato, I. and Gasco, L., 2017. Evaluation of the suitability of a partially defatted black soldier fly (Hermetia illucens L.) larvae meal as ingredient for rainbow trout (Oncorhynchus mykiss Walbaum) diets. Journal of Animal Science and Biotechnology 8(4): 957-969.

Sealey, W.M., Gaylord, T.G., Barrows, F.T., Tomberlin, J.K., McGuire, M.A., Ross, C. and St-Hilaire, S., 2011. Sensory analysis of rainbow trout, Oncorhynchus mykiss, fed enriched black soldier fly prepupae, Hermetia illucens. Journal of the World Aquaculture Society 42(1): 34-45.

Shiau, S.Y. and Yu, Y.P., 1999. Dietary supplementation of chitin and chitosan depresses growth in tilapia, Oreochromis niloticus $\times$ O. aureus. Aquaculture 179(1): 439-446.

Sun, C., Dong, H., Wang, W., Li, Y., Gu, Q., Duan, Y., Zhang, J. and $\mathrm{Xu}, \mathrm{X}$., 2021. Effects of glycerol monolaurate on lipid metabolism of Lateolabrax maculatus. South China Fisheries Science 17(1): 67-75.

Wang, G., Chen, B., Sun, Y., Hu, J., Peng, K., Wu, H. and Huang, Y., 2020. Effects of replacing fish meal with defatted black soldier fly (Hermetia illucens) larvae meal on growth performance, nutrient retention, serum biochemical parameters and digestive enzymes activity of juvenile Pelteobagrus fulvidraco. Journal of Fisheries of China 44(6): 987-998.

Wang, G., Peng, K., Hu, J., Yi, C., Chen, X., Wu, H. and Huang, Y., 2019. Evaluation of defatted black soldier fly (Hermetia illucens L.) larvae meal as an alternative protein ingredient for juvenile Japanese seabass (Lateolabrax japonicus) diets. Aquaculture 507: 144-154.

Wang, G., Peng, K., Hu, J., Mo, W., Wei, Z., Huang, Y., 2021. Evaluation of defatted Hermetia illucens larvae meal for Litopenaeus vannamei: effects on growth performance, nutrition retention, antioxidant and immune response digestive enzyme activity and hepatic morphology. Aquaculture Nutrition 27(4): 986-997. https://doi.org/10.1111/ anu. 13240

Xiao, X., Jin, P., Zheng, L., Cai, M., Yu, Z., Yu, J. and Zhang, J., 2018. Effects of black soldier fly (Hermetia illucens) larvae meal protein as a fishmeal replacement on the growth and immune index of yellow catfish (Pelteobagrus fulvidraco). Aquaculture Research 49(4): 1569-1577.

Xu, X., Ji, H., Yu, H. and Zhou, J., 2020. Influence of dietary black soldier fly (Hermetia illucens Linnaeus) pulp on growth performance, antioxidant capacity and intestinal health of juvenile mirror carp (Cyprinus carpio var. specularis). Aquaculture Nutrition 26: 432-443.

Yi, C., 2018. Effects of dietary fish oil replaced with black soldier fly (Hermetia illucens) larvae oil on the growth and lipid metabolism of yellow catfish (Peltobagrus fulvidraco). MSc-thesis, Hunan Agricultural University, Changsha, China.

Zhou, J., Liu, S., Ji, H. and Yu, H., 2017. Effect of replacing dietary fish meal with black soldier fly larvae meal on growth and fatty acid composition of Jian carp (Cyprinus carpio var. Jian). Aquaculture Nutrition 24: 424-433. 
